\title{
A FUNÇÃO DAS TEORIAS NA ESCRITA DA HISTÓRIA
}

RÜSEN, Jörn. Reconstrução do passado. Teoria da história II: os princípios da pesquisa histórica. Tradução de Asta-Rose Alcaide; revisão técnica de Estevão de Rezende Martins. Brasília: Ed. UnB, 2007, 188 p.

Diogo da Silva Roiz

Doutorando em História pela UFPR. Mestre em História pelo programa de pósgraduação da Unesp, campus de Franca. Professor do Departamento de História da Universidade Estadual de Mato Grosso do Sul (UEMS), campus de Amambai.

Parece ser cada vez mais comum a afirmação de que os historiadores estão hoje mais preocupados com as árvores do que com a floresta "da História". Em função do descrédito ao qual foram relegados os projetos de "história total" do passado, sendo substituídos por iniciativas que, na voraz expressão de François Dosse, tinham em comum estabelecer uma "história em migalhas", é que aquela afirmação tem ganhado um certo sentido. Para Jörn Rüsen, é justamente essa a função da teoria da história: permitir que o historiador possa ver a floresta que abrange as árvores da história, ao invés de se embrenhar nas árvores, despercebendo a floresta que as circunscrevem. Nesse sentido, a teoria da história seria não apenas um alicerce para que a História possa estar sendo elaborada por meio de uma pesquisa "cientificamente" conduzida, mas também ser um canteiro fértil para que o historiador possa verificar "as expectativas que foram criadas no passado sobre o futuro", de modo a proporcionar certos sentidos ao processo histórico, com os quais os homens e as mulheres do passado plasmaram suas ideias de "verdadeiro" e "falso".

Foi com esse objetivo que Jörn Rüsen se preocupou em circunstanciar uma teoria sistemática da história. Para articulá-la, tomou como base o conceito de “matriz disciplinar" desenvolvido por Thomas Kuhn (2003, p. 217-257) que o apresentou no posfácio de 1969 a seu livro A estrutura das revoluções científicas 
(originalmente publicado em 1962), no qual propôs substituir seu conceito de "paradigma". Rüsen, por sua vez, apoiou-se neste conceito para articular sua análise sobre a escrita da história, numa teoria sistemática e operacional (mas, talvez, até pela maneira com a qual o conceito de "paradigma" expresso por Thomas Kuhn foi veementemente criticado, e o autor o tenha substituído pelo de "matriz disciplinar", o leitor perceberá, senão uma confusão, ao menos um uso significativamente fluído e híbrido destes termos na obra de Rüsen).

Com esse propósito, procurou definir como "matriz disciplinar" o conjunto sistemático de fatores que prescrevem um processo dinâmico, que visam determinar os princípios constitutivos da ciência da história. Mais precisamente, a "matriz disciplinar" corresponderia à articulação de fatores que envolveriam a "vida prática" e a "ciência especializada", onde se passaria dos interesses (que orientam o fluxo do tempo e a maneira como os indivíduos definem seu agir) para as ideias (as perspectivas orientadoras da experiência sobre o passado, no presente histórico), e destas para os métodos (as regras da pesquisa empírica) que almejariam em seguida formas de apresentação do conhecimento histórico que teria como funções regular a orientação existencial dos indivíduos no tempo e lhes permitir tomadas de decisões. Nesse sentido, "articulados na matriz disciplinar da ciência da história, eles adquirem a especificidade que permite distinguir o pensamento histórico constituído cientificamente do pensamento histórico comum" (2001, p. 35), o que implicaria em reconhecer a especificidade do conhecimento histórico em "moldes científicos", sem negar a sua correspondente ligação com a "criação artística e literária", em função de seus resultados serem expostos, via de regra, por meio de "narrativas".

Foi justamente seguindo essas metas, que Rüsen dividiu sua obra Teoria da História em três volumes: Razão histórica, de 1983; Reconstrução do passado, de 1986; e História viva, de 1989. O primeiro foi traduzido no Brasil em 2001, e os outros dois em 2007 pela Editora da Universidade de Brasília (a UnB). No primeiro volume, Razão histórica, o autor se preocupou em: definir os princípios, as tarefas e as funções de uma teoria da história (cap. 1); verificar a constituição do pensamento histórico na vida prática, com vistas a delinear os critérios com os quais se define a verdade no pensamento histórico "com a intenção de esclarecer, a partir deles, o que significa fazer história como ciência" (cap. 2); analisar a constituição metódica da ciência da história, de modo a demonstrar a passagem da garantia de validade em geral, "que ocorre por princípio em toda narrativa histórica, para a garantia de validade característica 
da história como ciência" (cap. 3); e demonstrar, enfim, a constituição narrativa do sentido histórico (cap. 4).

No segundo volume, Reconstrução do passado, por sua vez, destaca a estrutura organizacional de uma teoria da história (cap. 1) e as regras específicas da pesquisa histórica (cap. 2). Com isso, procurou demonstrar como:

O pensamento histórico torna-se especificamente científico quando segue os princípios da metodização, quando submete a regras todas as operações da consciência histórica, cujas pretensões de validade se baseiam nos argumentos das narrativas, nas quais tais fundamentos são ampliados sistematicamente. [...] Se é o princípio da metodização que transforma o pensamento histórico em ciência, cabe perguntar apenas como se faz valer esse princípio nos diversos fatores da matriz disciplinar. Obtém-se, assim, uma ideia da construção da história como ciência especializada (2007, p. 12).

Por fim, no terceiro volume, História viva, estudou as diferentes maneiras de apresentação da historiografia, tendo em vista as várias formas de constituição de sentido (tradicional, exemplar, crítica e genética), quando a ciência se torna o princípio da forma de exposição dos resultados, por meio de uma narrativa (cap. 1), e caracterizou as funções do saber histórico, quando apreendida sua tarefa didática no campo dos estudos históricos e junto à sociedade (cap. 2).

Resumido o conjunto da obra, convém agora detalhar melhor o segundo volume, com o qual o autor visou demonstrar as regras sobre a reconstrução do passado, em moldes científicos.

Ao se propor tal tarefa, o autor ressalta que a constituição do conhecimento histórico em moldes especificamente científicos depende fundamentalmente das formas de organização e de apresentação dos procedimentos de pesquisa empírica, quando visam à reconstrução do passado, ainda que por meio de uma narrativa. Não foi por acaso, nesse sentido, que o autor passou em revista: a explicação nomológica e o problema das leis históricas, ao analisar o modelo de Hempel; a explicação intencional e o problema das articulações hermenêuticas de sentido, ao verificar o modelo de Donagan; a explicação narrativa e o problema dos construtos narrativos teóricos, de acordo com o modelo de Danto. De acordo com Rüsen, como "experiência temporal interpretada mediante a atribuição de sentido pela narrativa histórica, a história é sempre particular. Ela não pode ser concebida como universal sem deixar de ser história, isto é, estruturada narrativamente" (2007, p. 58). E ainda: 
Do ponto de vista da história da ciência (sobretudo no espaço de língua alemã), a ciência da história afirmou-se como disciplina independente no contexto do historicismo do século XIX, por oposição à filosofia da história desse tipo (primeiro à idealista, sobretudo à de Hegel, mais tarde, à materialista). Tais teorias eram consideradas (e ainda são, para muitos) como não-científicas, até inimigas da ciência, porque se desviam da importância da pesquisa histórica empírica (2007, p. 55).

O papel das teorias da história, portanto, foi o de gerar condições de possibilidade de exposição, ao serem fios condutores das histórias, das construções de processos temporais de sentido. Assim, não foi sem razão que o autor tenha se apoiado, em vários momentos, nas obras de Droysen, Weber, Popper e Kocka para descrever o potencial de plausibilidade do discurso histórico ao ser construído cientificamente, de modo a demonstrar as funções (explicativa, heurística, descritiva, periodizadora, explanatória, individualizante, comparativa, diferenciadora, crítica e didática) e as características (teóricas e conceituais) das teorias da história, para a elaboração da história científica. Por isso, nesse ponto dará importância à caracterização dos conceitos em história, que "não são históricos porque se referem ao passado, mas porque lidam com a relação intrínseca que existe, no quadro de orientação da vida prática presente, entre a lembrança do passado e a expectativa do futuro" (2007, p. 92). Desse modo, ao diferenciar os conceitos históricos, dos nomes próprios e das categorias históricas, indica que eles:

[...] são o recurso linguístico que aplicam perspectivas de interpretação histórica a fatos concretos e exprimem sua especificidade temporal. Designam, pois, a relevância que os estados de coisas referidos possuem, no contexto temporal, em conjunto com outros estados de coisas, e que não são designados por nomes próprios. Conceitos históricos mediam categorias e nomes próprios. Eles introduzem a realidade temporal dos estados de coisas designados por nomes próprios no contexto de sentido designado por categorias. Em relação às categorias históricas, eles possuem uma função generalizante. Eles fazem com que interpretações históricas gerais “convirjam” com a comprovação de fatos reais (2007, p. 94).

Mas ao abordar tais questões, com vistas a dar um caráter científico à pesquisa histórica, a apresentação de seus argumentos ganhou um contorno muito esquemático e pouco operacional. A organização do conhecimento histórico por meio da escrita da história necessita, portanto, do estabelecimento adequado dos procedimentos de pesquisa. O "método histórico", nesse sentido, se refere "a operações específicas de conhecimento conhecidas como 'pesquisa histórica' e 
abrange suas regras básicas", tal como foi definido e transformado em verdadeiro cânone doutrinal pela historiografia oitocentista. Na função que tem a pesquisa histórica, na constituição metodológica e expositiva do conhecimento histórico, o autor divide-a nas formas hermenêutica, analítica e dialética. Ao apresentar cada uma dessas formas, fica novamente a impressão de que a redução das formas de apresentação da historiografia apenas nesses modelos ocasionaria, não a apresentação científica de todas as formas do agir humano, mas sim a redução de sua ação e de suas atitudes em modelos historiográficos previamente estabelecidos. Por outro lado, para que a historiografia e a pesquisa histórica fossem apresentadas "em moldes científicos" no seu modelo interpretativo, o autor acabou por desconsiderar que o uso de estilos na escrita da história é também parte constituinte do ofício do historiador, já que a apresentação da pesquisa histórica em formas narrativas tem íntima relação com a criação literária e com a subjetividade do autor. $\mathrm{O}$ que não quer dizer, evidentemente, que a história seja mera "criação literária", nem unicamente "exposição científica".

Portanto, a leitura deste volume, como de toda a trilogia sobre teoria da história, permite ao leitor compreender os princípios da pesquisa histórica que visam reconstituir o passado por meio de métodos cientificamente organizados e peculiares à ciência da história. Ao fazer sua exposição, o autor demonstra ao leitor todas as etapas que estruturam e estabelecem as funções de uma teoria da história, e como ela está diretamente relacionada à elaboração das regras da pesquisa histórica. Evidentemente, pode-se criticar que em alguns momentos sua argumentação é demasiadamente esquemática e estrutural, que sua resposta às críticas de autores como Hayden White foram exageradamente simplificadas, ou que seus exemplos foram insuficientes para a demonstração sistemática da utilização prática de uma teoria da história na pesquisa histórica e na organização da narrativa. Mas isso não tira os méritos da obra. Muito pelo contrário, deve-se, desde já, valorizar esse tipo de iniciativa tão pouco praticado na historiografia pelos historiadores profissionais. E, no caso da obra de Jörn Rüsen, a valorização deve ser efetuada, principalmente, porque, ao demonstrar a necessidade constante dos historiadores organizarem seus procedimentos metodológicos em "moldes científicos", adequados numa exposição narrativa peculiar, este indica, ao mesmo tempo, a função dos historiadores na sociedade, ao constituírem meios para que esta se localize no tempo, compreenda os sentidos dos processos históricos e seu movimento dinâmico que muitas vezes cria uma fronteira tênue entre o "verdadeiro" e o "falso". 


\section{Referências bibliográficas}

RÜSEN, J. Reconstrução do passado. Teoria da História II: os principios da pesquisa histórica. Tradução de Asta-Rose Alcaide; revisão técnica de Estevão de Rezende Martins. Brasília: Ed. UnB, 2007.

RÜSEN, J. Razão histórica. Teoria da História I: os fundamentos da ciência da história. Tradução de Estevão de Rezende Martins. Brasília: Ed. UnB, 2001.

RÜSEN, J. História viva. Teoria da História III: formas e funções do conhecimento histórico. Tradução de Estevão de Rezende Martins. Brasília: Ed. UnB, 2007.

KUHN, T. S. A estrutura das revoluções cientificas. Tradução de Beatriz Vianna Boeira (et. el.). $7^{\mathrm{a}}$ ed. São Paulo: Editora Perspectiva, 2003.

Recebido: setembro/2008 - Aprovado: junho/2009. 